\title{
Variation in the behavioral responses of Budgerigars Melopsittacus undulatus to an alarm call in relation to sex and season
}

\author{
GÉRARD NICOLAS, CLOÉ FRAIGNEAU and THIERRY AUBIN \\ NAMC CNRS UMR 8620, Université Paris-Sud, Bât. 446, 91405 Orsay Cedex, France \\ Manuscript received on January 15, 2004; accepted for publication on February 5, 2004.
}

\begin{abstract}
In the Budgerigar Melopsittacus undulatus, the significance of a conspecific alarm call was investigated in two seasons, winter and spring. Two qualitatively different behavioral responses were displayed by the receivers in reply to playbacks: call(s) and/or taking flight(s). The comparative analysis of the number of birds responding to the alarm and to the control signals revealed two major facts: 1) in both seasons, the responses to the alarm signal were only observed for females, not for males, 2) qualitatively, females exhibited a great inter-season variability in their behavioral responses to the hearing of an alarm call. In winter, the females were more predisposed to emit acoustic responses while in spring they mainly took flight.
\end{abstract}

Key words: Budgerigars, alarm call, sex, season, response plasticity.

\section{INTRODUCTION}

The understanding of acoustic communication requires study of both call production by emitters and call perception by receivers. The exchange of a given amount of information between a sender and a receiver is only the first step of a communication process.

For a receiver, the significance of the information encoded in a signal depends not only on what can be heard, but also critically on the context in which the information is received (Bradbury and Vehrencamp 1998). The significance attached to a signal by the receiver is revealed by its subsequent actions. Playback is a powerful method to understand the significance of an acoustic signal. Birds often respond to natural stimuli by predictable responses (Cynx and Clark 1998). This is the case in

Correspondence to: Gérard Nicolas

E-mail: gerard.nicolas@ibaic.u-psud.fr the territorial defense in response to a simulated intrusion (see Becker 1982 for a review) or in individual recognition between mates and between parents and young in noisy colonies of swallows (Beecher et al. 1986), seabirds (Falls 1982, Mathevon et al. 2003) or penguins (Aubin and Jouventin 2002). Most of these works concerned birds studied during the breeding season. In our work, we report that the responses of Budgerigars Melopsittacus undulatus to playback of a conspecific call are not predictable throughout the year and are subjected to qualitative behavioral modulations. The budgerigars are suitable candidates for bioacoustic studies. They have a complex vocal repertoire and the functions of their vocalizations are known (Brockway 1964a, b, 1965, Dooling et al. 1990, Farabaugh and Dooling 1996). Among these vocalizations, the alarm call is one of the most used signals in the vocal repertoire of this species. It is produced when birds are disturbed, in 

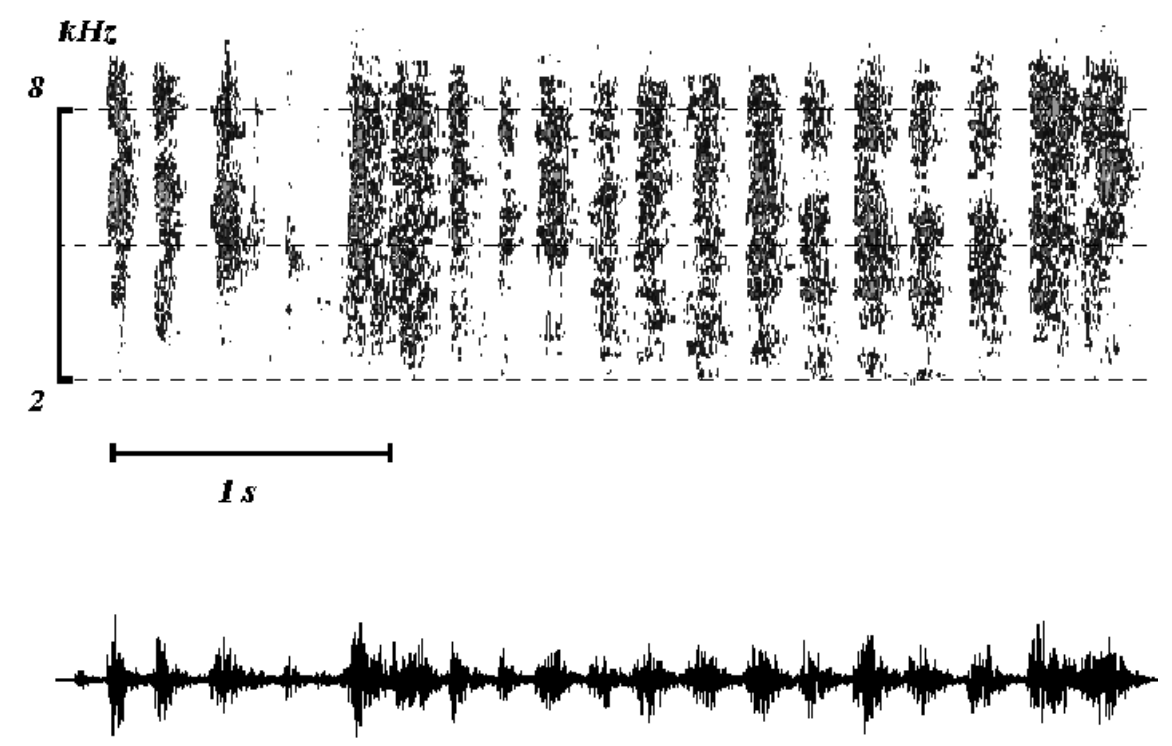

Fig. 1 - Sonogram and oscillogram of an alarm call (AL) of a Budgerigar Melopsittacus undulatus, used in the study.

agonistic encounters and is one of the components of the warble song (Brockway 1964b, Farabaugh et al. 1992). The aim of this study was to compare the behavioral responses of males and females to the playback of alarm calls in two distinct seasons: the breeding period and the non-breeding period.

\section{MATERIALS AND METHODS}

The experiments were performed in spring (March and April, i.e. the beginning of the breeding season in Europe) and in winter (December and January, i.e. non-breeding season).

Subjects. 49 unmated birds (9 to 14 months old) were used: 28 in spring (20 females, 8 males) and 21 in winter ( 13 females, 8 males). The difference between the number of females $(n=33)$ and males $(n=16)$ was imposed by the sex ratio of the previous breeding season.

Stimuli. The played back alarm call (AL) of 3.4 seconds duration was composed of 19 syllables. Syllable duration ranged from 85 to $110 \mathrm{~ms}$ and the inter-syllables silence from 10 to $70 \mathrm{~ms}$ (Fig. 1). In preliminary experiments we observed that the budgerigars displayed identical qualitative responses to hearing 2 alarm calls produced by 2 different individuals, which minimizes problems of pseudo replication (McGregor et al. 1992). To take in account a possible signal effect, an experimental control sound (CS) was constructed by synthesis using Syntana software (Aubin 1994). It consisted of a discontinuous frequency at $2220 \mathrm{~Hz}$, containing an equal number of syllables and the same intersyllables silences as those of AL. The $2220 \mathrm{~Hz}$ value corresponds to the frequency band of greatest hearing sensitivity of the species (Dooling 1973).

Procedure. 12 hours before the experiment, each tested bird was isolated from the group and put into a cage $(23 \times 35 \times 40 \mathrm{~cm})$ located in a distant experimental test room. Signals were presented in the test chamber at a natural Sound Pressure Level of $75 \mathrm{~dB}_{\text {SPL }}$ measured at $1 \mathrm{~m}$ of the bird's head. The background noise was of $42 \mathrm{~dB}_{\mathrm{SPL}}$. The two acoustic signals were presented successively and at random with a 5-min silent period interval and at six determined times each day separated by a $1 \mathrm{~h}$ interval. Each set began when the birds were silent and 
quiet. The vocal and postural responses of the birds to the playbacks were audio and video recorded and then analyzed. Depending on the value set, the MacNemar test or the sign test was used to compare the different experimental situations.

\section{RESULTS}

\section{Global Analysis on the Significance} of the Alarm Call (Table I)

A first global indication on the significance of the alarm call was obtained from the responses of the four experimental populations: males and females, in spring and in winter. In response to the alarm signal, 17 birds emitted calls in reply and 15 took flight. In response to the CS these numbers were respectively 3 and 2. Among the birds responding to alarm calls, only 5 of them exhibited both qualitative behavioral responses. So, without distinction of the type of response (either at least a call in reply and/or taking flight) significantly many more birds responded to the $\mathrm{AL}(27 / 49=55.1 \%)$ than to the $\mathrm{CS}$ $\left(5 / 49=10.2 \%\right.$; MacNemar: $\left.\chi^{2}=20.05, \mathrm{P}<0.001\right)$. Among the birds reacting to the alarm call, a majority $(22 / 27=81.5 \%)$ responded exclusively by calls in reply $(12 / 22=54.5 \%)$ or by taking flight $(10 / 22=$ $45.5 \%$ ). Based on the equal distribution of these different behavioral responses, more precise analyses were undertaken, in order to prove if these different responses are related to the season, or to the sex.

\section{Seasonal Variation (Table II)}

At the population level, males and females pooled, in spring and in winter, the signal effect was always expressed but not at the same qualitative level of response. In spring, the level of response to the alarm call was only revealed by the number of birds taking flight $(11 / 28=39.3 \%$ in response to AL, $2 / 28$ $=7.1 \%$ in response to CS; MacNemar test: $\chi^{2}=$ $7.11, \mathrm{P}=0.007)$, but not by the number of those responding with calls $(3 / 28=10.7 \%$ to $\mathrm{AL}, 0 / 28$ to $C S$; sign test: $\mathrm{Z}=1.155, \mathrm{P}=0.25$ ). In winter, the level of response to the alarm call was revealed by the number of birds responding by calls $(14 / 21$
$=66.7 \%$ birds in response to $\mathrm{AL}, 3 / 21=14.3 \%$ to CS; MacNemar test: $\left.\chi^{2}=9.09, \mathrm{P}=0.003\right)$, but not by the number of birds taking flight $(4 / 21=19 \%$ in response to $\mathrm{AL}, 0 / 21=0 \%$ to $\mathrm{CS}$; sign test: $\mathrm{Z}=$ $1.50, \mathrm{P}=0.133)$.

\section{Sex Variation (Table II)}

In regard to the sex, the significance of the alarm call was only given by the females, never by the males. In addition, the proportion of responses to alarm call differs significantly according to the season. In spring, 55\% (11/20) of the females displayed a flight in response to the $\mathrm{AL}, 10 \%(2 / 20)$ in response to the CS (MacNemar test: $\chi^{2}=7.11, \mathrm{P}=0.008$ ); only $10 \%(2 / 20)$ of them emitted calls in reply to alarm and none $(0 / 20)$ to the CS playback (sign test: $\mathrm{Z}=$ 0.707, $\mathrm{P}=0.479$ ). In winter, for $\mathrm{AL}$ and $\mathrm{CS}$ perception respectively, $15.4 \%(2 / 13)$ and $0 \%(0 / 13)$ of these females took flight (sign test: $\mathrm{Z}=0.707$, $P=0.48)$, while $76.9 \%(10 / 13)$ emitted calls in response to AL and $23.1 \%$ (3/13) in response to CS (MacNemar: $\chi^{2}=5.14, \mathrm{P}=0.023$ ).

\section{DISCUSSION}

This work compared the number of males and females budgerigars displaying qualitatively different behavioral responses (calls in reply or taking flight) to the alternative playbacks of a conspecific alarm signal (AL) or of a pure tone control sound (CS) in spring and winter. It gives some new insights into the sexual discriminative capabilities of this parrot species. In particular, the alarm message was shown to only be effective for the females, not for the males. For budgerigars, in a different experimental context of operant conditioning, a sex difference in the perception of another conspecific call, the contact call, has also been reported (Okanoya and Dooling 1991). From these results, it seems that the information encoded in different biologically significant conspecific calls may be decoded differently by males and females of this species. In songbirds, sexual differences in the decoding of a song are also known (Dabelsteen and Pedersen 1988, Searcy and 
TABLE I

Global population analysis. Number of budgerigars displaying responses to the playback of a conspecific alarm call (AL) or of a control sound (CS). Numbers of responding males $(M)$ and females $(F)$ in spring and in winter are pooled.

\begin{tabular}{l|c|c|c|cc}
\hline & AL & CS & $N$ & $\begin{array}{c}\text { Comparison } \\
\text { AL-CS }\end{array}$ \\
\hline Call(s) in reply & 17 & 3 & 49 & $* * *$ & $(\mathrm{a})$ \\
Taking flight(s) & 15 & 2 & 49 & $* * *$ & $(\mathrm{a})$ \\
Both call(s) and taking flight(s) & 5 & 0 & 49 & NS & $(\mathrm{b})$ \\
Call(s) and/or taking flight(s) & 27 & 5 & 49 & $* * *$ & $(\mathrm{a})$ \\
Only call(s) or only taking flight(s) & 22 & 5 & 49 & $* * *$ & $(\mathrm{~b})$ \\
Only call(s) in reply & 12 & 3 & 22 & $* *$ & $(\mathrm{~b})$ \\
Only taking flight(s) & 10 & 2 & 22 & $*$ & $(\mathrm{~b})$ \\
\hline
\end{tabular}

Comparisons: MacNemar (a) or Sign (b) tests. NS: non significant, $*: \mathrm{p}<0.05$, $* *: \mathrm{p}<0.01, * * *: \mathrm{p}<0.001$.

TABLE II

Sexual and seasonal distributions of the number of budgerigars responding by call(s) in reply or by taking flight(s).

\begin{tabular}{|c|c|c|c|c|c|}
\hline & & Spring & Winter & \multicolumn{2}{|c|}{$\begin{array}{c}\text { Comparison } \\
\text { AL-CS }\end{array}$} \\
\hline & & AL $\quad \mathrm{CS}$ & AL $\quad \mathrm{CS}$ & Spring & Winter \\
\hline \multirow{3}{*}{$M+F$} & & $N=28$ & $N=21$ & & \\
\hline & Call(s) in reply & 0 & 14 & NS (b) & $* *$ (a) \\
\hline & Taking flight(s) & 11 & 4 & $* *$ (a) & NS (b) \\
\hline \multirow{3}{*}{$\mathrm{F}$} & & $N=20$ & $N=13$ & & \\
\hline & Call(s) in reply & 0 & 10 & $\mathrm{NS}(\mathrm{b})$ & $*(b)$ \\
\hline & Taking flight(s) & 11 & 2 & $*(a)$ & NS (a) \\
\hline \multirow{3}{*}{ M } & & $\underline{N=8}$ & $\underline{N=8}$ & & \\
\hline & Call(s) in reply & 0 & 4 & $\mathrm{NS}(\mathrm{b})$ & NS (b) \\
\hline & Taking flight(s) & 0 & 2 & NS (b) & NS (b) \\
\hline
\end{tabular}

Comparisons: MacNemar (a) or Sign (b) tests. NS: non significant, $*: p<0.05$, $* *: \mathrm{p}<0.01, * * *: \mathrm{p}<0.001$

Brenowitz 1988). For these authors, the differences on the responses observed for the sexes were related to propagation constraints. In our case, conditions of propagation were similar during experiments for both sexes and this correlation cannot be argued.
If we only take into account the number of birds responding by taking flight, the fact that the hearing of an alarm call does not elicit particular behavioral response in males does not mean that they are unable to discriminate this call from the control sound. A 
work in progress, in which the postural events are quantified from a graded series of responses ranging from what could be a single phonotaxic response (variation of head orientation) up to flight, leads us to the conclusion that more subtle measures of behavioral response have to be taken into account. Moreover, our observations outlined the necessity to use a set of different quantitative and qualitative parameters. Effectively, as seen for the female budgerigars, a seasonal effect can be detected for different kinds of behaviors, in response to hearing an alarm call: either calls in reply in winter or taking flight in spring. As the same amount of information (the same alarm call) was provided in both seasons, the mechanisms underlying such seasonal variations, as well as the sexual differences, in the behavioral responses to hearing an alarm call may involve sensory as well as neural or physiological factors.

\section{RESUMO}

O significado de um grito de alarme do Periquito-australiano Melopsittacus undulatus foi investigado em duas estações, inverno e primavera. Duas reações comportamentais, qualitativamente diferentes, foram apresentadas pelos receptores em resposta ao play-back: grito(s) e/ou vôo(s). A análise comparativa do número de aves respondendo ao grito de alarme e aos sinais de controle revelou dois fatos principais: 1) em ambas as estações, as respostas ao grito de alarme foram observadas somente para as fêmeas, não para os machos, 2) qualitativamente, as fêmeas mostraram uma grande variação estacional nas suas respostas comportamentais à escuta de um grito de alarme. No inverno, as fêmeas eram mais predispostas a emitir uma resposta acústica, enquanto na primavera elas geralmente levantavam vôo.

Palavras-chave: Periquito-australiano, grito de alarme, sexo, estação, plasticidade de resposta.

\section{REFERENCES}

Aubin T. 1994. Syntana: a software for the synthesis and analysis of animal sounds. Bioacoustics 1: 187-208.

Aubin T And Jouventin P. 2002. How to vocally identify kin in a crowd; the penguin model. Adv Study Behav 31: 243-277.
BECKER PH. 1982. The coding of species-specific characteristics in birds sounds. In: KRoodsma DE ANd Miller EH. (Eds), Acoustic Communication in Birds: Vol 1. New York: Academic Press, p. 213-252.

Beecher D, Melvin MB, Stoddard PK and Loesch P. 1986. Acoustic adaptation for parent offspring recognition in swallows. J Exp Biol 45: 179-193.

Bradbury JW and Vehrencamp SL. 1998. Principles of Animal Communication. Sunderland, MA: Sinauer Associates Inc.

BROCKWAY BF. 1964a. Social influences on reproductive physiology and ethology of Budgerigars Melopsittacus undulatus. Anim Behav 12: 493-501.

Brockway BF. 1964b. Ethological studies of the Budgerigar Melopsittacus undulatus: non-reproductive behavior. Behavior 22: 192-222.

BrockWAY BF. 1965. Stimulation of ovarian development and egg laying by male courtship vocalization in Budgerigars Melopsittacus undulatus. Anim Behav 13: 575-578.

Cynx J And Clark SJ. 1998. The Laboratory Use of Conditional and Natural Responses in the Study of Avian Auditory Perception. In: Hopp SL, Owren MJ And Evans CS. (Eds), Animal acoustic communication. Berlin: Springer Verlag, p. 353-377.

Dabelsteen T and Pedersen SB. 1988. Do females Blackbirds, Turdus merula, decode song in the same way as males? Anim Behav 36: 1858-1860.

Dooling RJ. 1973. Behavioral audiometry with the parakeet Melopsittacus undulatus. J Acoust Soc Am 53: 1757-1758.

Dooling RJ, Brown SD, Park TJ And OKanoya K. 1990. Natural perceptual categories for vocal signals in Budgerigars. In: SteBbins WC AND BerKLEY MA. (Eds), Comparative Perception, Vol 2, Communication. New York: J Wiley and sons, p. 345-374.

FALLS JB. 1982. Individual recognition by sounds in birds. In: Kroodsma DE and Miller EH. (Eds), Acoustic Communication in Birds: Vol 1. New York: Academic Press, p. 237-278.

FARABAugh SM and Dooling RJ. 1996. Acoustic Communication in Parrots: Laboratory and Field Studies of Budgerigars, Melopsittacus undulatus. In: Kroodsma DE And Miller EH. (Eds), Ecology and 
Evolution of Acoustic Communication in Birds. Ithaca: Cornell University Press, p. 97-117.

Farabaugh SM, Brown ED And Dooling RJ. 1992. Analysis of warble song of the Budgerigar Melopsittacus undulatus. Bioacoustics 4: 111-130.

Mathevon N, Charrier I and Jouventin P. 2003. Potential for individual recognition in acoustic signals: a comparative study of two gulls with different nesting patterns. CR Acad Sci 326: 329-337.

McGregor PK, Catchrole CK, Dabelsteen T, Falls JB, Fusani L, Gerhart hC, Gilbert R, Horn AG, Klump GM, Kroodsma DE, Lambrechts MM, McСomb KE, Nelson DA, Pepperberg IM,
Ratcliffe L, Searcy WA AND Weary DM. 1992. Design of playback experiments: the Thorn-bridge hall NATO ARW Consensus. In: McGREgOR PK. (Ed), Playback and studies of animal communication. New York: Plenum Press, p. 1-9.

OKanoya K And Dooling RJ. 1991. Perception of Distance Calls by Budgerigars (Melopsittacus undulatus) and Zebra Finches (Poephila guttata): Assessing Species-Specific Advantages. J Comp Psychol 105: 60-72.

Searcy W and Brenowitz EA. 1988. Sexual differences in species recognition of avian song. Nature 332: $152-154$. 